\title{
Gastric Cancer Staging with Radiologic Imaging Modalities and UICC Staging System
}

\author{
Hye Seong Ahn ${ }^{a}$ Se Hyung Kim ${ }^{b}$ Yasuhiro Kodera ${ }^{d}$ Han-Kwang Yang ${ }^{c}$ \\ ${ }^{a}$ Department of Surgery, Seoul National University Boramae Hospital, Departments of ${ }^{b}$ Radiology and ${ }^{\mathrm{C}}$ Surgery and \\ Cancer Institute, Seoul National University College of Medicine, Seoul, Korea; ${ }^{d}$ Department of Gastroenterological \\ Surgery, Nagoya University Graduate School of Medicine, Nagoya, Japan
}

\section{Key Words}

Gastric cancer · Laparoscopy · Stage classification system

\begin{abstract}
There are two major stage classification systems for gastric cancer: the tumor-node-metastasis (TNM) stages by the International Union against Cancer (UICC) and the Japanese Classification of Gastric Carcinoma by the Japanese Gastric Cancer Association (JGCA). Preoperative stage classification using either of these systems is essential for deciding on the treatment strategy in the era of various multimodal therapeutic options. Evolution of multidetector computerized tomography with isotropic volumetric imaging and various 3D images has increased the accuracy of $\mathrm{T}$ and $\mathrm{N}$ staging in patients with gastric cancer, although detection of peritoneal deposits and nodal metastasis in the absence of lymphadenopathy remain problematic with the imaging tools currently available. The TNM and JGCA classifications have undergone revisions independent of each other, and the discrepancies were not helpful when international comparisons and cooperation were needed. More recently, the JGCA and TNM classifications were merged to have identical $\mathrm{T}$ and $\mathrm{N}$ categories, in addition to the more straightforward $\mathrm{M}$ categories that indicate the presence of distant metastasis. The result of
\end{abstract}

these efforts is that researchers in Japan and the rest of the world are now looking at a similar disease when they discuss cancer that belongs to the same stage. A nomogram that incorporates other established prognostic determinants in addition to the TNM component may be a future direction for a more sophisticated means of predicting outcome. The increasing incidence of junctional (esophagogastric junction) cancer in the Far East has spurred researchers from this region to adequately stage the disease and to consider suitable treatment modalities for this disease entity, whereas Western researchers are more inclined to treat this disease as esophageal cancer. This could be an area for future international debate. For the next more accurate staging, we suggest the collaboration between Eastern and Western highvolume centers in gastric cancer because the inconsistency of surgical approaches, especially with respect to nodal resection, remains a barrier to mutual understanding.

Copyright $\odot 2013$ S. Karger AG, Basel

\section{Introduction}

Adequate preoperative stage classification is essential for deciding on the treatment strategy and selecting the optimal type of surgery. Accurate postoperative stage

\section{KARGER}

E-Mail karger@karger.com

www.karger.com/dsu
(C) 2013 S. Karger AG, Basel

0253-4886/13/0302-0142\$38.00/0
Prof. Han-Kwang Yang, MD, PhD, FACS

Department of Surgery and Cancer Research Institute

Seoul National University Hospital, Seoul National University, College of Medicine

28 Yeongeon-dong, Jongno-gu, Seoul 110-744 (South Korea)

E-Mail hkyang@snu.ac.kr 
classification is useful for estimation of prognosis and making decisions on postoperative treatment modalities. Imaging studies, computed tomography (CT) in particular, have developed substantially over the last decade to offer a more accurate diagnosis for the three major categories of the tumor-node-metastasis (TNM) stages by the International Union against Cancer (UICC) [1]. The exception, however, is still the diagnosis of peritoneal seeding for detection of which staging laparoscopy has been increasingly in demand.

Accurate postoperative stage classification is important when treatment outcomes are compared between the institutions or at the setting of multi-institutional studies. This is more difficult when a comparison has to be made between different countries adapting different classification schemes. Japan has compiled and used complicated staging systems where extended lymphadenectomy is necessary for decent $\mathrm{N}$ classification [2]. More recently, the Japanese $\mathrm{N}$ classification scheme has merged with the TNM system to facilitate international comparison and cooperation. This review provides a brief overview of the current status in the imaging modalities based on which preoperative staging are made and describes the past, present, and future of major stage classification systems, of which the continuation of international cooperative efforts to control gastric cancer will be based.

\section{Radiologic Staging for Gastric Cancer}

Currently, the standard staging modalities for gastric cancer are endoscopic ultrasonography (EUS), CT, magnetic resonance imaging (MRI), positron emission tomography (PET) or PET/CT, and diagnostic laparoscopy. EUS has the ability to image five distinct wall layers with histologic correlation and to assess regional lymph node involvement in addition to local tumor infiltration; however, EUS is not suitable for detecting distant metastases, including the liver and peritoneum. By virtue of rapid advancement in CT technologies such as multidetector CT (MDCT) and 3D visualization software, CT becomes a powerful imaging tool for noninvasive evaluation of the stomach and can assess locoregional and metastatic staging simultaneously. Current MDCT with isotropic volumetric imaging and various $3 \mathrm{D}$ images has increased the accuracy of $\mathrm{T}$ and $\mathrm{N}$ staging in patients with gastric cancer. Volume-rendering images including transparent or surface-rendering images enable radiologists to detect subtle mucosal abnormalities and provide an overview of the lesion in the stomach. Coronal and sagittal multiplanar reformatted images permit radiologists to select the optimal imaging plane to accurately evaluate tumor invasion depth of the gastric wall and perigastric infiltration, and to differentiate lymph nodes from small perigastric vessels [3].

For $\mathrm{T}$ staging, the staging accuracy is reported to be higher with MDCT including coronal and sagittal multiplanar reformatted images or with volume-rendering CT gastrography than with conventional $2 \mathrm{D}$ axial CT images. Although the stomach is histologically composed of five layers (mucosa, submucosa, proper muscularis, subserosa, and serosa), the gastric wall is generally detected as three layers on CT: mucosal layers with high attenuation, submucosal layers with low attenuation, and musculoserosal layers with high attenuation. T1a has a tendency not to be visualized on 2D CT images and appears as a subtle mucosal irregularity on $3 \mathrm{D}$ volume-rendering images. T1b shows mucosal thickening with enhancement and has a preserved low-attenuation stripe at the base of the lesion corresponding to the submucosal layer (fig. 1) [4]. T2 appears as a thickened gastric wall with loss or disruption of a low-attenuation stripe but a clear and smooth outer gastric surface around the lesion. T3 demonstrates a transmural, full-thickness enhancement with wall thickening. The differentiation of T3 and T4a on CT images is difficult because the serosa of the gastric wall is not visible on CT images and subserosal adipose tissue is different from person to person. However, perigastric fat infiltration around the lesion indicates T4a rather than T3. Direct invasion of a tumor into a contiguous organ or structure on CT images is diagnosed as a T4b tumor.

For $\mathrm{N}$ staging, lymph nodes are considered positive when the short axis diameter is greater than $6 \mathrm{~mm}$ for perigastric nodes and greater than $8 \mathrm{~mm}$ for extraperigastric lymph nodes. Other criteria for malignant nodes include a round shape, loss of the normal fatty hilum, and marked or heterogeneous enhancement. However, CT accuracy for $\mathrm{N}$ staging (51-84\%) is not satisfactory because microscopic involvement may not increase the size of lymph nodes and reactive lymph nodes can be enlarged up to $2 \mathrm{~cm}$.

Given the importance of cost-effectiveness, enhanced chest/abdominal MDCT with isotropic volumetric imaging and various $3 \mathrm{D}$ images should be considered the most useful radiologic imaging modality needed for preoperative staging of gastric cancer (fig. 2). Additionally, information on vascular anatomy is available through this modality, and this will facilitate lymphadenectomy procedures both in open and laparoscopic surgery. When a patient is considered a candidate for curative surgery, a 

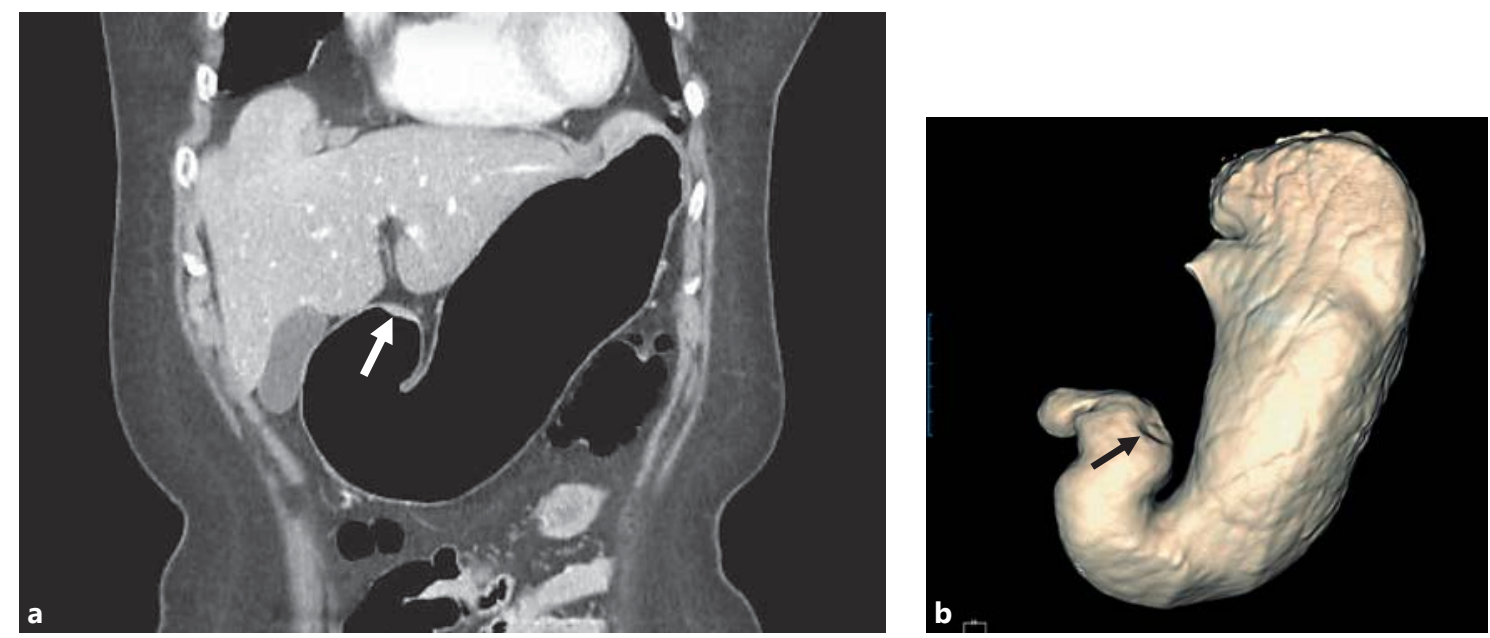

Fig. 1. MDCT images of early gastric cancer in a 65-year-old woman. a Coronal reformatted CT image shows an enhancing mucosal thickening (arrow) at the greater curvature side of the gastric antrum. Note the well-preserved low attenuating stripe around the lesion, suggesting preserved submucosal layer. b, c 3D surface-rendered image (b) and virtual endoscopic view (c) of CT gastrography demonstrate a focal elevating lesion (arrow) at the corresponding area. Laparoscopy-assisted distal gastrectomy confirmed an early gastric cancer with submucosa invasion (T1b, sm2).

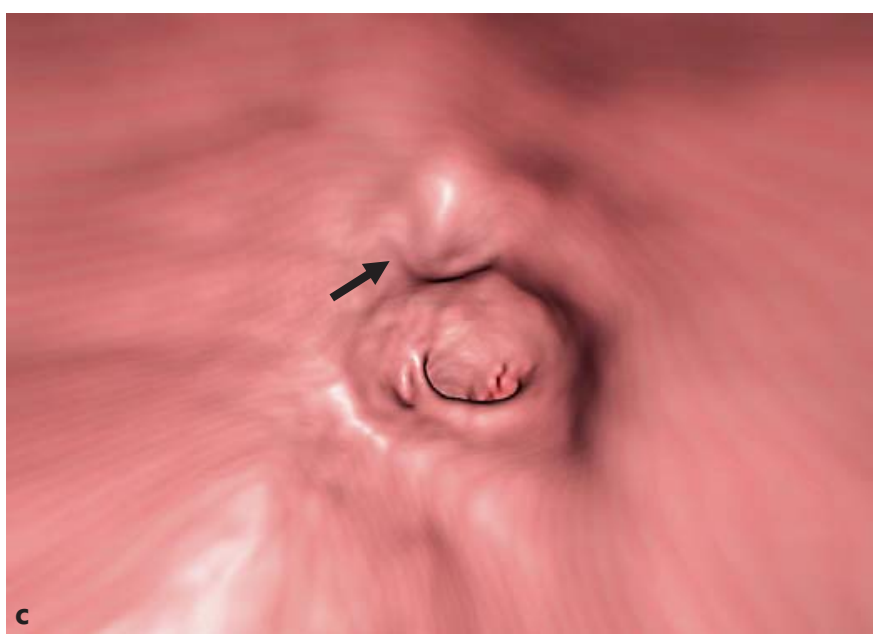

PET scan is useful to rule out unexpected distant metastases and EUS could be useful for more precise T staging. Both of the modalities are recommended for work-up by the National Comprehensive Cancer Network (NCCN) guidelines for gastric cancer. At this time, MRI should be spared for patients who are clinically suspected of having liver metastasis. Bone scintigrams and brain scans should be considered as clinically indicated.

\section{Staging Laparoscopy}

Although not a radiologic imaging modality, the importance of staging laparoscopy needs to be mentioned since it is an essential component of preoperative workup for gastric cancer. Laparoscopy can detect radiographically occult peritoneal metastases and prevent futile lap- arotomy in patients with gastric carcinoma. Furthermore, peritoneal washes for cytologic examination which detects endoscopically occult peritoneal metastases can be performed through a laparoscopic approach. In the Surveillance, Epidemiology and End Results (SEER) population-based cancer registry data, staging laparoscopy was performed in $7.9 \%$ patients who had any surgery, and $29.8 \%$ of these patients did not have a subsequent therapeutic intervention [5]. Leake et al. [6] found in a systematic review that surgery was avoided in $8.5-43.8 \%$ of cases that underwent staging laparoscopy. Considering the etiology of peritoneal metastases, staging laparoscopy should be performed at least for patients with clinically T4M0 status. In addition, the information that a patient is without any peritoneal deposits should be as accurate as possible in clinical trials to test a neoadjuvant chemotherapy. 


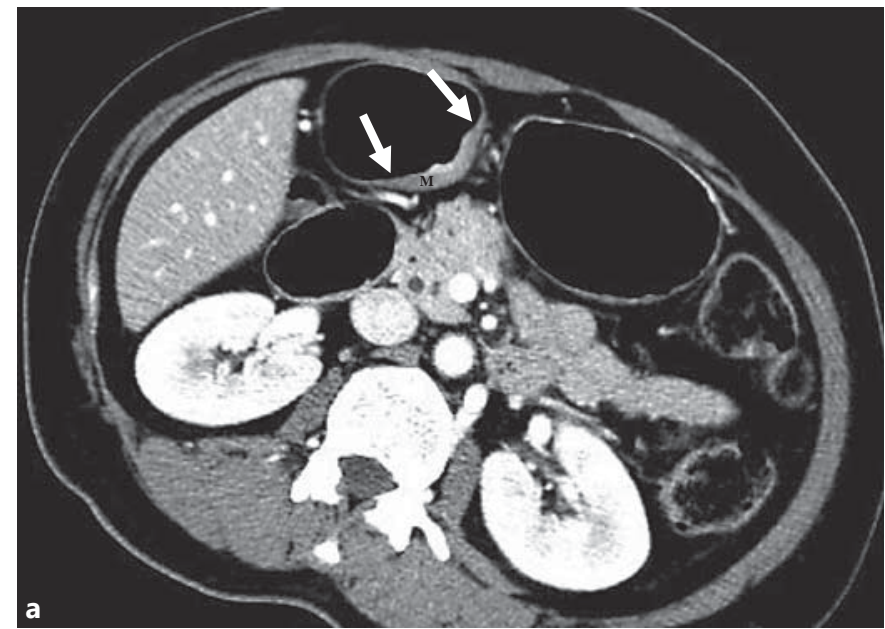

Fig. 2. MDCT images of advanced gastric cancer in a 48-year-old woman. a Axial CT image demonstrates an enhancing wall thickening at the lesser curvature of the gastric antrum (arrows). Intermediate high attenuating muscle layer $(\mathrm{M})$ is also thickened, suggesting invasion to the muscle layer. However, the outer margin is

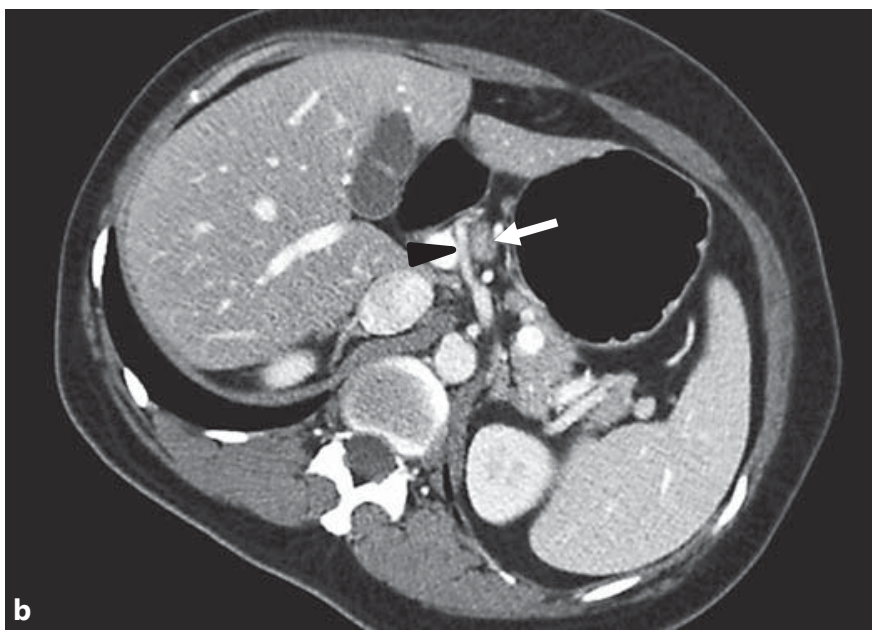

smooth and well-defined. b On an axial CT image $4 \mathrm{~cm}$ cranial to a, there is an enlarged lymph node (arrow) near the common hepatic artery (arrowhead). Subtotal gastrectomy confirmed the diagnosis of advanced gastric cancer (pT2N1).

\section{UICC/AJCC TNM Staging System}

\section{Previous Staging Systems}

The UICC/AJCC TNM classification and the Japanese system are the two main staging systems representing Western countries and Japan, respectively. Although the UICC/AJCC TNM classification of the local spread of gastric carcinoma was identical to the Japanese system, the classification of lymph node metastasis and resulting stage grouping of these systems was different until 2010 [7-9]. The 1st edition of the Japanese classification of lymphatic spread describes four groups (N1-N4) based on the anatomic station of the lymph nodes in relation to the location of the primary tumor. The 5th UICC/AJCC TNM classification of regional lymph node metastasis is based on the anatomic location in relation to the primary tumor [pN1: metastasis in perigastric lymph node(s) within $3 \mathrm{~cm}$ of the edge of the primary tumor; $\mathrm{pN} 2$ : metastasis in perigastric lymph node(s) more than $3 \mathrm{~cm}$ from the edge of primary tumor lymph nodes or along the left gastric, common hepatic, splenic, or celiac artery]. However, it was very difficult for pathologists to discriminate between these two entities ( $\mathrm{pN} 1$ and $\mathrm{pN} 2$ ) because of the surgical technique of en bloc resection for gastric cancer and the shrinkage of the specimen after fixation in formalin [10]. Furthermore, the individual lymph node stations in Japan were usually classified by the surgeon and sent to the pathologist in separate individually labeled con- tainers, whereas in Western countries the anatomic localization of lymph node metastases was usually determined by the pathologist based on the formalin-fixed en bloc resected specimen. Consequently, international comparisons of treatment results that took the different anatomic extents of disease into consideration were not possible.

To overcome these difficulties in the classification of regional lymph metastasis, the 5th UICC/AJCC TNM staging system adopted the $\mathrm{N}$ stage determined by the number of metastatic lymph nodes rather than by the lymph node location [10-12]. After this significant change, many reported the effectiveness and superiority for prognostic stratification $[10,13,14]$. This $\mathrm{N}$ classification based on the number of involved lymph nodes could be applied worldwide without methodological problems and was expected to increase the reproducibility of assessment and provide improved prognostic information.

The 6th UICC/AJCC TNM staging system had only small changes in which proper muscle tumors and subserosal tumors were amended into $\mathrm{T} 2 \mathrm{a}$ and $\mathrm{T} 2 \mathrm{~b}$, respectively $[15,16]$. Until this staging system, a tumor in which half was below esophagogastric junction (EGJ) was classified as gastric in origin $[15,16]$.

\section{Current Staging System}

The 7th UICC/AJCC TNM staging system adopted some changes in TNM classification (table 1) and clarifies the staging system tumor around EGJ $[1,17]$. 
Table 1. Differences in T, N, and M staging between the 6 th and 7 th classification systems

\begin{tabular}{|c|c|c|c|c|c|c|c|}
\hline & & & \multicolumn{4}{|c|}{ M0 } & \multirow[t]{3}{*}{ M1 } \\
\hline \multicolumn{2}{|c|}{6 th } & & No & $\mathrm{N} 1$ & $\mathrm{~N} 2$ & N3 & \\
\hline & & Involved LN, $\mathrm{n}$ & 0 & $1-6$ & $7-15$ & $\geq 16$ & \\
\hline \multirow{5}{*}{ M0 } & $\mathrm{T} 1$ & Mucosa, submucosa & IA & IB & II & IV & IV \\
\hline & $\mathrm{T} 2 \mathrm{a}$ & Muscularis propria & \multirow{2}{*}{ IB } & \multirow{2}{*}{ II } & \multirow{2}{*}{ IIIA } & \multirow{2}{*}{ IV } & \multirow{2}{*}{ IV } \\
\hline & $\mathrm{T} 2 \mathrm{~b}$ & Subserosa & & & & & \\
\hline & T3 & Serosa & II & IIIA & IIIB & IV & IV \\
\hline & $\mathrm{T} 4$ & Adjacent structure & IIIA & IV & IV & IV & IV \\
\hline \multicolumn{3}{|l|}{ M1 } & IV & IV & IV & IV & IV \\
\hline
\end{tabular}

\begin{tabular}{|c|c|c|c|c|c|c|c|c|}
\hline & & & \multicolumn{5}{|c|}{ M0 } & \multirow[t]{3}{*}{ M1 } \\
\hline \multirow{2}{*}{\multicolumn{2}{|c|}{ 7th }} & & No & N1 & $\mathrm{N} 2$ & N3a & $\mathrm{N} 3 \mathrm{~b}$ & \\
\hline & & Involved LN, $\mathrm{n}$ & 0 & $1-2$ & $3-6$ & $7-15$ & $\geq 16$ & \\
\hline \multirow{5}{*}{ M0 } & $\mathrm{T} 1$ & Mucosa, submucosa & IA & IB & IIA & IIB & IIB & IV \\
\hline & $\mathrm{T} 2$ & Muscularis propria & IB & IIA & IIB & IIIA & IIIA & IV \\
\hline & T3 & Subserosa & IIA & IIB & IIIA & IIIB & IIIB & IV \\
\hline & $\mathrm{T} 4 \mathrm{a}$ & Serosa & IIB & IIIA & IIIB & IIIC & IIIC & IV \\
\hline & $\mathrm{T} 4 \mathrm{~b}$ & Adjacent structure & IIIB & IIIB & IIIC & IIIC & IIIC & IV \\
\hline \multicolumn{3}{|l|}{ M1 } & IV & IV & IV & IV & IV & IV \\
\hline
\end{tabular}

As for the changes in TNM classification, the first is the definition of stage IV. Distant metastasis is now considered an incurable factor and was separated to stage IV, and positive washing cytology is now considered as M1. This addition can bring an important change to the management of patients who may otherwise undergo a futile operation. Patients with positive cytology have shown identical outcomes to the patients with distant metastasis in both Western and Eastern countries [18]. Secondly, the previous subgroups $\mathrm{pT} 2 \mathrm{a}$ (muscularis propria) and $\mathrm{pT} 2 \mathrm{~b}$ (subserosa) have now been classified as pT2 (muscularis propria) and pT3 (subserosa). It was reflected in the report that tumors invading the muscularis propria and those invading the subserosa had different prognoses [19,
20]. In addition, a more precise lymph node classification has been adopted. pN1 (1-6 involved regional lymph nodes) in the 6th system was amended into new groups: pN1 (1-2 involved regional lymph nodes) and pN2 (3-6 involved regional lymph nodes). Furthermore, the pN2 (7-15 involved regional lymph nodes) and $\mathrm{pN} 3$ (more than 15 involved regional lymph nodes) groups in the 6th system were mergerd into a new $\mathrm{pN} 3$ group (more than 6 involved regional lymph nodes).

Many reports have validated and supported the 7th staging system [21-25]. Most of the studies found the 5 -year survival rates for each 7th TNM stage to be significantly different from each other, based mostly on Asian populations, and they found that it provides a more 
precise classification of prognosis than the 6th edition, especially regarding $\mathrm{pT} 2$ and $\mathrm{pT} 3$ tumors and $\mathrm{pN} 1$ and pN2 tumors [21-24]. Studies using Western populations also concluded the superiority of the new edition $[25,26]$. Furthermore, the Japanese Gastric Cancer Association (JGCA) made a big decision to adopt the $\mathrm{N}$ stage determined by the number of metastatic lymph nodes [27]. These changes made comparison of results between countries easier.

Although tumors with more than 6 involved regional lymph nodes have been merged to a new $\mathrm{pN} 3$ in the 7 th classification, the 5-year survival rate for patients with 7-15 involved regional lymph nodes was significantly different from that with more than 15 involved regional lymph nodes in a recent study [28]. Many others have also reported that $\mathrm{N}$ staging in 6th system is more optimal than that in the 7th system in Eastern populations [2931 ]. Some suggest that the 7 th system is more complex but does not improve the predictability for overall survival in Western populations $[32,33]$. In addition, there have been reports about the lack of information regarding the extent of lymph node dissection and difficulty in its application to surgical treatment planning with the $\mathrm{N}$ staging system. Although it does not affect stage allocation, dividing $\mathrm{N} 3$ as N3a (7-15) and N3b (>15) is maintained in the 7th edition for future classification. On the other hand, the idea of $\mathrm{N}$ classification with a positive lymph node ratio has been continuously dealt with in many studies [34-37].

Only continuing accumulation of data will allow us to analyze what the cutoff number is of metastatic lymph nodes with significant prognostic difference as well as enable us to determine which is better: the numeric classification or lymph node ratio. For the first time, the International Gastric Cancer Association (IGCA) was involved in the revision of the 6th edition of the TNM staging system for gastric cancer for the 7 th edition and is now running a task force for the next revision. Patient data from major centers in the East and West have been collected now and a more universal and reasonable staging system is expected to be formulated and proposed from these data.

As for EGJ cancers, only the cancers whose epicenter in the stomach is greater than $5 \mathrm{~cm}$ distal to the EGJ or those within $5 \mathrm{~cm}$ of the EGJ but not extending into the EGJ or esophagus are classified according to the gastric cancer staging system. All other cancers whose epicenter is in the lower thoracic esophagus, EGJ, or within the proximal $5 \mathrm{~cm}$ of the stomach (cardia) that extend into the EGJ or esophagus are staged as adenocarcinoma of the esophagus $[1,17]$. Therefore, small cardia cancer within $5 \mathrm{~cm}$ but apart from the EGJ is classified as gastric cancer, but it can be staged according to esophageal cancer after it grows enough to reach to the EGJ. This esophageal cancer staging came from an assembled worldwide database from three continents to overcome the previous esophageal cancer staging system which had problems of empiric stage grouping and lack of harmonization with stomach cancer [38-40].

Like these reference databases, some reports have supported that adenocarcinomas of the cardia and distal esophagus could be classified together because of the many similarities between them $[41,42]$. However, there have been some proposals that carcinoma of the cardia is a type of gastric cancer which must be treated or classified according to criteria for gastric cancer surgery [43-45]. The extremely different incidence of esophageal adenocarcinoma, EGJ cancer, and gastric cancer in Western and Eastern countries has limited the well-designed comparative research. The reference data for esophageal cancer staging were collected through the Worldwide Esophageal Cancer Collaboration in which there were only two Eastern hospitals among the 48 participating institutions and about $65 \%$ of the data used for the analysis was collected before 2000 [38-40]. Moreover, the Japanese population that represents the Eastern population usually has a much shorter length of the lesser curvature (about 15-20 cm) than Americans, who represent the Western population [46]. Considering distance criteria from the 7th staging system, there is only a very small area remaining for the upper third of the stomach after excluding the upper $5 \mathrm{~cm}$ of both the lesser and greater curvatures for EGJ cancer. Recently, Suh et al. [47] reported that an EGJ tumor with an epicenter located in the stomach showed a very similar prognosis with gastric cancer, irrelevant to the involvement of the EGJ, using a database of Korean institutes. Again, the upcoming IGCA taskforce proposal for the future TNM staging system will include this issue too.

The reference database was collected on the outcome for surgery alone as the therapy. Chemotherapy and radiation therapy have not been directly compared with one another, nor have enough GEJ tumors been treated to power a direct comparison [48]. Only accumulation of data on outcomes for each stage, particularly in patients undergoing neoadjuvant treatment, will allow better classification in the future to guide treatment.

\section{Other Staging Systems}

The TNM classification of the UICC/AJCC and the Japanese classification by the JGCA considered only the 
depth of invasion, the number of metastatic lymph nodes, and distant metastasis. However, other factors such as age, sex, size of the tumor, location, and differentiation could be considered for predicting individualized survival. Nomograms have been developed to quantify risk by combining prognostic factors in some diseases. There is a nomogram for gastric cancer patients based on a Western database and validated in a Western population [4951]. Recently Han et al. [52] developed and externally validated a nomogram predicting 5- and 10-year overall survival after D2 gastrectomy for gastric cancer based on an Eastern database. Using these nomograms with many significant clinicopathologic variables, the prognosis of patients with gastric cancer can be more precisely predicted than when using TNM stage.

\section{Conclusion}

The 7th UICC/AJCC TNM staging system for gastric cancer improves the $\mathrm{T}$ designations and the prognostic stratification of the $\mathrm{N}$ status and has added clearer definitions for M1 disease to optimize treatment options. For the next more accurate staging, we suggest the collaboration between Eastern and Western high-volume centers in gastric cancer because the inconsistency of surgical approaches, especially with respect to nodal resection, remains a barrier to staging patients after resection despite induction therapy. As for EGJ cancer, issues persist, although the 7th UICC/AJCC TNM staging system aimed to improve harmonization of gastric and distal esophageal/EGJ adenocarcinomas.

\section{References}

1 TNM Classification of Malignant Tumors, ed 7. Oxford, Wiley-Blackwell, 2009.

2 Sano T, Aiko T: New Japanese classifications and treatment guidelines for gastric cancer: revision concepts and major revised points. Gastric Cancer 2011;14:97-100.

-3 Lee MH, Choi D, Park MJ, Lee MW: Gastric cancer: imaging and staging with MDCT based on the 7th AJCC guidelines. Abdom Imaging 2012;37:531-540.

4 Lee IJ, Lee JM, Kim SH, Shin CI, Le JY, Kim SH, Han JK, Choi BI: Diagnostic performance of 64-channel multidetector CT in the evaluation of gastric cancer: differentiation of mucosal cancer (T1a) from submucosal involvement (T1b and T2). Radiology 2010;255:805814.

5 Karnicolas PJ, Elkin EB, Jacks LM, Atoria CL, Strong VE, Brennan MF, Coit DG: Staging laparoscopy in the management of gastric cancer: a population-based analysis. J Am Coll Surg 2011;213:644-651.

6 Leake PA, Cardoso R, Seevaratnam R, Lourenco L, Helyer L, Mahar A, Law C, Coburn NG: A systematic review of the accuracy and indications for diagnostic laparoscopy prior to curative-intent resection of gastric cancer. Gastric Cancer 2012;15(suppl 1):S38-S47.

7 Beahrs OH, Henson DE, Hutter RVP, Kennedy BJ (eds): Manual for Staging of Cancer. American Joint Committee on Cancer, ed 4. Philadelphia, JB Lippincott, 1992.

$\checkmark 8$ Hermanek P, Sobin LH (eds): TNM Classification of Malignant Tumours. International Union against Cancer, ed 4, 2nd revision. Berlin, Springer, 1992.

9 Nishi M, Omori Y, Miwa K (eds): Japanese Classification of Gastric Carcinoma. Japanese Research Society for Gastric Cancer (JRSGC), ed 1 (English). Tokyo, Kanehara \& Co., 1995.
10 Roder JD, Bottcher K, Busch R, Wittekind C, Hermanek P, Siewert JR: Classification of regional lymph node metastasis from gastric carcinoma. German Gastric Cancer Study Group. Cancer 1998;82:621-631.

11 Sobin LH, Wittekind CH (eds): TNM Classification of Malignant Tumours. International Union against Cancer, ed 5. New York, John Wiley \& Sons, 1997.

12 Fleming ID, Cooper JS, Henson DE, et al (eds): Manual for Staging of Cancer. American Joint Committee on Cancer, ed 5. Philadelphia, JB Lippincott, 1997.

13 Ichikura T, Tomimatsu S, Uefuji K, Kimura M, Uchida T, Morita D, Mochizuki H: Evaluation of the New American Joint Committee on Cancer/International Union against Cancer classification of lymph node metastasis from gastric carcinoma in comparison with the Japanese classification. Cancer 1999;86: 553-558.

$\checkmark 14$ Kodera Y, Yamamura Y, Shimizu Y, Torii A, Hirai T, Yasui K, Morimoro T, Kato T, Kito $\mathrm{T}$ : Lymph node status assessment for gastric carcinoma: is the number of metastatic lymph nodes really practical as a parameter for $\mathrm{N}$ categories in the TNM Classification? Tumor Node Metastasis. J Surg Oncol 1998;69:15-20.

15 Sobin LH, Wittekind CH: TNM Classification of Malignant Tumors, ed 6. New York, WileyLiss, 2002.

16 Greene FL, Page DL, Fleming ID (eds): Manual for Staging of Cancer. American Joint Committee on Cancer, ed 6. New York, Springer, 2002.

17 Edge SB BD, Compton CC, et al: AJCC Cancer Staging Handbook, ed 7. New York, Springer, 2010.

18 Mezhir JJ, Shah MA, Jacks LM, Brennan MF, Coit DG, Strong VE: Positive peritoneal cytol- ogy in patients with gastric cancer: natural history and outcome of 291 patients. Ann Surg Oncol 2010;17:3173-3180.

19 Park do J, Kong SH, Lee HJ, Kim WH, Yang $\mathrm{HK}$, Lee KU, Choe KJ: Subclassification of pT2 gastric adenocarcinoma according to depth of invasion (pT2a vs pT2b) and lymph node status (pN). Surgery 2007;141:757-763.

-20 Nitti D, Marchet A, Mocellin S, Rossi GM, Ambrosi A, Mencarelli R: Prognostic value of subclassification of T2 tumours in patients with gastric cancer. Br J Surg 2009;96:398404.

21 Wang W, Sun XW, Li CF, Lv L, Li YF, Chen YB, Xu DZ, Kesari R, Huang CY, Li W, Zhan YQ, Zhou ZW: Comparison of the 6th and 7th editions of the UICC TNM staging system for gastric cancer: results of a Chinese single-institution study of 1,503 patients. Ann Surg Oncol 2011;18:1060-1067.

-22 Kim SS, Choi BY, Seo SI, Jung MY, Choi HS, Ahn SM, Choi WH, Kim HS, Kim KH, Jang MK, Lee JH, Kim HY, Shin W: The comparison between 6 th and 7 th International Union against Cancer/American Joint Committee on Cancer Classification for Survival Prognosis of Gastric Cancer (in Korean). Korean J Gastroenterol 2011;58:258-263.

23 Kikuchi S, Futawatari N, Sakuramoto S, Katada N, Yamashita K, Shibata T, Nemoto M, Watanabe M: Comparison of staging between the old (6th edition) and new (7th edition) TNM classifications in advanced gastric cancer. Anticancer Res 2011;31:2361-2365.

24 Fang WL, Huang KH, Chen JH, Lo SS, Hsieh MC, Shen KH, Li AF, Niu DM, Chiou SH, Wu $\mathrm{CW}$ : Comparison of the survival difference between AJCC 6th and 7th editions for gastric cancer patients. World J Surg 2011;35:27232729. 
25 McGhan LJ, Pockaj BA, Gray RJ, Bagaria SP, Wasif N: Validation of the updated 7th edition AJCC TNM staging criteria for gastric adenocarcinoma. J Gastrointest Surg 2012;16: 53-61.

26 Marrelli D, Morgagni P, de Manzoni G, Coniglio A, Marchet A, Saragoni L, Tiberio G, Roviello F, Italian Research Group for Gastric Cancer (IRGGC): Prognostic value of the 7th AJCC/UICC TNM classification of noncardia gastric cancer: analysis of a large series from specialized Western centers. Ann Surg 2012; 255:486-491.

-27 Japanese Gastric Cancer Association: Japanese classification of gastric carcinoma: 3rd English edition. Gastric Cancer 2011;14:101112.

28 Ahn HS, Lee HJ, Hahn S, Kim WH, Lee KU, Sano T, Edge SB, Yang HK: Evaluation of the seventh American Joint Committee on Cancer/International Union Against Cancer Classification of gastric adenocarcinoma in comparison with the sixth classification. Cancer 2010;116:5592-5598.

29 Jung H, Lee HH, Song KY, Jeon HM, Park $\mathrm{CH}$ : Validation of the seventh edition of the American Joint Committee on Cancer TNM staging system for gastric cancer. Cancer 2011;117:2371-2378.

30 Yoon HM, Ryu KW, Nam BH, Cho SJ, Park SR, Lee JY, Lee JH, Kook MC, Choi IJ, Kim YW: Is the new seventh AJCC/UICC staging system appropriate for patients with gastric cancer? J Am Coll Surg 2012;214:88-96.

- 31 Zhang J, Niu Z, Zhou Y, Cao S: A comparison between the seventh and sixth editions of the American Joint Committee on Cancer/International Union against Classification of Gastric Cancer. Ann Surg 2013;257:81-86.

32 Dikken JL, van de Velde CJ, Gonen M, Verheij M, Brennan MF, Coit DG: The new American Joint Committee on Cancer/International Union against Cancer staging system for adenocarcinoma of the stomach: increased complexity without clear improvement in predictive accuracy. Ann Surg Oncol 2012;19:2443-2451.

-33 Reim D, Loos M, Vogl F, Novotny A, Schuster T, Langer R, Becker K, Hofler H, Siveke J, Bassermann F, Friess H, Schuhmacher C: Prognostic implications of the seventh edition of the International Union against Cancer classification for patients with gastric cancer: the Western experience of patients treated in a single-center European institution. J Clin Oncol 2013;31:263-271.
34 Kong SH, Lee HJ, Ahn HS, Kim JW, Kim WH, Lee KU, Yang HK: Stage migration effect on survival in gastric cancer surgery with extended lymphadenectomy: the reappraisal of positive lymph node ratio as a proper $\mathrm{N}$-staging. Ann Surg 2012;255:50-58.

35 Santiago JR, Osorio J, Gutierrez I, Perez N, Mufioz E, Veloso E, Marco C: Prognostic usefulness of lymph node ratio in understaged gastric cancer. Hepatogastroenterology 2009; 56:1557-1561.

36 Persiani R, Rausei S, Antonacci V, Biondi A, Casella F, Ciccoritti L, D’Ugo D: Metastatic lymph node ratio: a new staging system for gastric cancer. World J Surg 2009;33:21062111.

37 Rodriguez Santiago JM, Munoz E, Marti M, Quintana S, Veloso E, Marco C: Metastatic lymph node ratio as a prognostic factor in gastric cancer. Eur J Surg Oncol 2005;31:59-66.

38 Rice TW, Blackstone EH, Rusch VW: A cancer staging primer: esophagus and esophagogastric junction. J Thorac Cardiovasc Surg 2010;139:527-529.

39 Rice TW, Rusch VW, Ishwaran H, Blackstone $\mathrm{EH}$ : Cancer of the esophagus and esophagogastric junction: data-driven staging for the seventh edition of the American Joint Committee on Cancer/International Union against Cancer Cancer Staging Manuals. Cancer 2010;116:3763-3773.

40 Ishwaran H, Blackstone EH, Apperson-Hansen C, Rice TW: A novel approach to cancer staging: application to esophageal cancer. Biostatistics 2009;10:603-620.

-41 Wijnhoven BP, Siersema PD, Hop WC, van Dekken H, Tilanus HW: Adenocarcinomas of the distal oesophagus and gastric cardia are one clinical entity. Rotterdam Oesophageal Tumour Study Group. Br J Surg 1999;86:529_ 535.

42 MacDonald WC, MacDonald JB: Adenocarcinoma of the esophagus and/or gastric cardia. Cancer 1987;60:1094-1098.

43 Husemann B: Cardia carcinoma considered as a distinct clinical entity. Br J Surg 1989;76: 136-139.
44 Kodera Y, Yamamura Y, Shimizu Y, Torii A, Hirai T, Yasui K, Morimoto T, Kato T: Adenocarcinoma of the gastroesophageal junction in Japan: relevance of Siewert's classification applied to 177 cases resected at a single institution. J Am Coll Surg 1999;189:594-601.

45 Siewert JR, Feith M, Werner M, Stein HJ: Adenocarcinoma of the esophagogastric junction: results of surgical therapy based on anatomical/topographic classification in 1,002 consecutive patients. Ann Surg 2000;232 353-361.

46 Goldsmith HS, Akiyama H: A comparative study of Japanese and American gastric dimensions. Ann Surg 1979;190:690-693.

$\checkmark 47$ Suh YS, Han DS, Kong SH, Lee HJ, Kim YT, Kim WH, Lee KU, Yang HK: Should adenocarcinoma of the esophagogastric junction be classified as esophageal cancer? A comparative analysis according to the seventh AJCC TNM classification. Ann Surg 2012;255:908915

48 Strong VE, D’Amico TA, Kleinberg L, Ajani J: Impact of the 7th edition AJCC staging classification on the NCCN clinical practice guidelines in oncology for gastric and esophageal cancers. J Natl Compr Canc Netw 2013; 11:60-66.

49 Peeters KC, Kattan MW, Hartgrink HH, Kranenbarg EK, Karpeh MS, Brennan MF, van de Velde CJ: Validation of a nomogram for predicting disease-specific survival after an $\mathrm{R} 0$ resection for gastric carcinoma. Cancer 2005;103:702-707.

-50 Kattan MW, Karpeh MS, Mazumdar M, Brennan MF: Postoperative nomogram for disease-specific survival after an R0 resection for gastric carcinoma. J Clin Oncol 2003;21: 3647-3650.

51 Novotny AR, Schuhmacher C, Busch R, Kattan MW, Brennan MF, Siewert JR: Predicting individual survival after gastric cancer resection: validation of a US-derived nomogram at a single high-volume center in Europe. Ann Surg 2006;243:74-81.

52 Han DS, Suh YS, Kong SH, Lee HJ, Choi Y, Aikou S, Sano T, Park BJ, Kim WH, Yang HK: Nomogram predicting long-term survival after D2 gastrectomy for gastric cancer. J Clin Oncol 2012;30:3834-3840. 